\title{
Clinical Presentation and Survival of Smear-positive Pulmonary Tuberculosis Patients of a University General Hospital in a Developing Country
}

\author{
Anna CC Carvalho/ ${ }^{+}$, Zoelete B Nunes, Marneili Martins, Rodrigo OC Araújo, \\ Mario Comelli*, Alessandra Marinoni*, Afrânio L Kritski \\ Unidade de Pesquisa em Tuberculose, Serviço de Pneumologia, Hospital Universitário Clementino Fraga Filho, Universidade \\ Federal do Rio de Janeiro, Av. Brigadeiro Trompowsky s/noำ, Ilha do Fundão, 21941-590 Rio de Janeiro, RJ, Brasil \\ *Scuola di Specializzazione in Statistica Sanitaria, Università degli Studi di Pavia, Pavia, Italy
}

From January 1995 to August 1997 we evaluated prospectively the clinical presentation, laboratory findings and short-term survival of smear-positive pulmonary tuberculosis (TB) patients who sought care at our hospital. After providing informed, written consent, the patients were interviewed and laboratory tests were performed. Information about survivorship and death was collected through September 1998. Eighty-six smear-positive pulmonary TB patients were enrolled; $26.7 \%$ were HIV-seropositive. Seventeen HIV-seronegative pulmonary TB patients (19.8\%) presented chronic diseases in addition to TB. In the multiple logistic regression analysis a CD4+ cell count $\leq 200 \mathrm{cell} / \mathrm{mm}^{3}$ was independently associated with HIV seropositivity. In the Cox regression model, fitted to all patients, HIV seropositivity and age $\geq 50$ years were independently associated with decreased survival. Among HIVseronegative persons, the presence of an additional disease increased the risk of death of almost six-fold. Use of antiretroviral drugs was associated with a lower risk of death among HIV-seropositive smear-positive pulmonary $T B$ patients $(R H=0.32,95 \%$ CI 0.10-0.92). In our study smear-positive pulmonary TB patients had a low short-term survival rate that was strongly associated with HIV infection, age and co-morbidities. Therapy with antiretroviral drugs reduced the short-term risk of death among HIV-seropositive patients after TB diagnosis.

Key words: tuberculosis - HIV infection - survival

Tuberculosis (TB) continues to be a significant public health problem in middle and low income countries. The World Health Organization (WHO) estimated that there were 122,000 TB cases in Brazil in 1997, the 13th highest number of cases in a single country worldwide (Dye et al. 1999). In the same year, the reported prevalence rate of TB cases in the city of Rio de Janeiro was 174 per 100,000 population, and the rate of new, incident cases was 120/ 100,000 , more than twice the incidence rate of TB cases nationwide $(50.9 / 100,000)$ (Cavalcante et al. 1998, Dye et al. 1999). The high incidence and prevalence of TB in Rio de Janeiro are likely due to several factors, among them an increase in the number of persons who are coinfected with TB and the human immunodeficiency virus (HIV) (Szwarcwald et al. 1998).

The national TB program in Brazil focuses its activities in the community-based primary health care centers, which are responsible for the diagnosis and treatment of the majority of TB patients. However, since the expansion of the epidemic of the acquired immunodeficiency syndrome (AIDS), an increasing number of TB cases have been diag-

Support: World Bank/STD/AIDS Program, Ministry of Health, Brazil. Contracts 003/94, CNPq 521130/95 and Faperj 26/ 170718/95.6. First author is a fellow of Capes-Brasília, Brazil. ${ }^{+}$Corresponding author. Fax: +55-21-2270.6893. E-mail: upt@ hucff.ufrj.br

Received 25 March 2002

Accepted 15 October 2002 nosed and treated in general hospitals, which often lack a structured TB program. In the period from 1995 to 1997 , $33 \%$ of notified TB cases in the city of Rio de Janeiro originated in hospital units (Cavalcante et al. 1998).

The objective of our study was to evaluate the clinical presentation, laboratory findings and short-term survival of smear-positive pulmonary TB patients by HIV infection serostatus among a hospital-based population in an urban area with a high incidence of TB, Rio de Janeiro city.

\section{STUDY POPULATION AND METHODS}

From January 1995 to August 1997, all pulmonary TB patients with a positive acid-fast bacilli (AFB) from respiratory specimens who sought care at the Clementino Fraga Filho University General Hospital of the Federal University of Rio de Janeiro (HUCFF/UFRJ) were eligible for inclusion in this study. This hospital provides care for an average of $300 \mathrm{~TB}$ patients annually, $50 \%$ to $60 \%$ of whom are diagnosed with pulmonary TB. Approximately half of these are smear-positive cases. The university hospital is also a state reference center for AIDS diagnosis and treatment.

After obtaining written, informed consent, all the patients included in the study were interviewed with a standardized questionnaire and laboratory tests were performed during the first two weeks after TB diagnosis. The questionnaire contained information about each patient's social and demographic characteristics, clinical symptoms, behavioral risks factors for HIV infection, and prior history of TB. Alcoholism was defined as at least two posi- 
tive answers to any of the four questions of the CAGE screening test (Steinweg \& Worth 1993). Laboratory tests included HIV serology (ELISA and Western Blot, for confirmation of positive results), CD4+ cell count by flow cytometry, a single tuberculin skin test (TST), delayed hypersensitivity skin tests (candida and tetanus toxoid), and chest radiography. Anergy was defined as the absence of any induration with the described skin tests. The TST was performed by trained, experienced nurses and consisted of $2 \mathrm{TU}$ of purified protein derivative (PPD) tuberculin RT 23 (Serum Institute, Denmark) applied by the Mantoux method. The size of the induration was read 48-72 $\mathrm{h}$ later by a trained nurse and was considered positive for an induration $\geq 10 \mathrm{~mm}$ ( $\geq 5 \mathrm{~mm}$ for HIV-seropositive patients). Chest radiographs were evaluated in a blinded fashion by radiologists and the findings were classified as typical for TB (focal infiltrates, nodular densities and/or cavities) or atypical (miliar infiltrates, diffuse infiltrates, hilar/mediastinal limphadenopathy or a normal radiography). Laboratory diagnosis of TB was based on the presence of acid fast bacilli (AFB) on one or more smears of expectorated sputum, induced sputum or in a specimen from bronco-alveolar lavage, stained by the Ziehl-Neelsen method. Cultures for mycobacteria, speciation and drug sensitivity analysis were not available in our hospital during the study period.

The main outcome variable of interest was survival. Information about patient's course from TB diagnosis to death, if it occurred, was collected from repeat consultations during anti-TB treatment, medical records reviews at the hospital, and/or telephone calls and household visits to the patients' families till September 1998. Autopsies were not performed and the exact cause of death was usually unknown.

We estimated the association between categorical variables and the outcomes using the chi-square or Fisher's exact test, when appropriate. The chosen level of significance was $5 \%$. The odds ratios (OR) of the association of various clinical, laboratory and sociodemographic variables to HIV seropositivity, with their respective 95\% confidence intervals, were calculated. Regression models to identify the predictors of HIV seropositivity were constructed using all the variables that were significant in the univariate analysis $(P<0.05)$. The Kaplan-Meier estimates were used to analyze the probabilities of survival among HIV-seronegative and HIV-seropositive pulmonary TB patients; these survival distributions were compared with the log-rank test. The influence of clinical characteristics (type and duration of symptoms, previous TB treatment, use of antiretroviral drugs, associated co-morbidities, alcoholism), laboratory characteristics (total lymphocyte count, CD4+ cell count, radiographic findings, response to skin tests) and sociodemographic characteristics (age, gender, race, socioeconomic level) on survival was analyzed using Cox regression models. We used dBase software for data collection and management and SPSS 7.0 for Windows for statistical analyses.

\section{RESULTS}

During the study period 389 pulmonary TB cases were diagnosed in our hospital; 191 (49.1\%) corresponded to smear-positive cases. We were able to contact 109 (28\%) of the 389 pulmonary TB cases, of whom 8 refused to take part in the study and 15 were persistently sputum smearnegative. Eight-six (45\%) smear-postive TB patients agreed to take part in the study. There were no significant differences in age and sex distribution between the pulmonary TB patients included and those not included in the study when TB notifications forms were compared (data not shown).

From 86 patients enrolled in the study $68.6 \%$ were male and $64 \%$ were of white race/ethnicity. Sixty-six percent were ambulatory outpatients when they were enrolled. The median age was 37 years (range 18-76 years). Sixtytwo patients $(72.1 \%)$ reported no risk behavior for HIV infection; 7 (11.9\%) were HIV-seropositive. Being a homosexual male $(5.8 \%)$ and having more than five sexual partners/year (10.5\%) were the most common risk factors for HIV infection reported. The other HIV risk factors referred were bisexuality (4.6\%), blood transfusion (3.5\%), sexual partner with risk factors for HIV infection (2.3\%), and intravenous drug use (1.2\%).

HIV infection was detected in 23 pulmonary TB patients $(26.7 \%)$. In 17 of these patients $(73.9 \%)$ another AIDS-defining condition was present when TB was diagnosed. Antiretroviral therapy was initiated after TB diagnosis in 16 (69.6\%) HIV-seropositive patients; only one patient used antiretroviral drugs before tuberculosis was diagnosed and 7 (41.2\%) used protease inhibitors after anti-TB treatment had finished. Additional diseases were present in the $17 \mathrm{HIV}$-seronegative pulmonary TB patients (19.8\%): diabetes mellitus $(n=4)$, cardiopathies $(n=4)$, cancer $(n=3)$, autoimmune diseases $(n=3)$, chronic hepatic dysfunction $(\mathrm{n}=2)$, and chronic obstructive pulmonary disease $(\mathrm{n}=1)$. Alcoholism was reported by 14 (16.3\%) patients with TB.

The median CD4+ cell count among 75 pulmonary TB patients was 548 cells $/ \mathrm{mm}^{3}$. Among $17 \mathrm{HIV}$-seropositive pulmonary TB patients that had a CD4+ cell count performed, $7(41.2 \%)$ had values $\leq 50 / \mathrm{mm}^{3}, 11(64.7 \%)$ had values $\leq 200 / \mathrm{mm}^{3}, 3(17.65 \%)$ were within $201-499 / \mathrm{mm}^{3}$, and $3(17.65 \%)$ were $\geq 500 / \mathrm{mm}^{3}$. HIV-seropositive pulmonary TB patients frequently had atypical chest radiography findings $(63.6 \%), 80 \%$ were unresponsive to PPD, $50 \%$ were anergic $\left(60 \%\right.$ of these had CD4 $\left.+\leq 200 / \mathrm{mm}^{3}\right)$ and $52.2 \%$ had a total lymphocyte count $\leq 1000 / \mathrm{mm}^{3}$.

The expectorated sputum smear for AFB was positive in 79 patients. In addition, one patient had induced sputum that was AFB positive and six had a bronchoalveolar lavage with a positive AFB smear (4 HIV-seronegative patients). Eight pulmonary TB patients reported a prior history of TB treatment; 7 of these 8 patients were HIVseronegative. Fever was the most commonly reported symptom $(63 / 86 ; 73.3 \%)$, followed by cough for more than four weeks $(57 / 86 ; 66.3 \%)$.

We obtained follow-up information about treatment from 77 patients $(89.5 \%)$, based on medical records review. From 77 patients, 59 (76.6\%) used combined isoniazid and rifampicin for at least six months and pyrazinamide for the initial two months; $6(7.8 \%)$ defaulted from treatment, and $12(15.6 \%)$ completed their TB treatment in other health-care units. 
In the univariate analysis, pulmonary TB patients with a negative PPD skin test, anergy, $25 \leq$ age $<45$ years, total lymphocyte count $\leq 1000 / \mathrm{mm}^{3}$, CD4+ cell count $\leq 200 /$ $\mathrm{mm}^{3}$, and an atypical chest radiograph were more likely to be HIV-seropositive than pulmonary TB patients without those characteristics (Table). In the multiple logistic regression analysis, only CD4+ cell count $\leq 200 \mathrm{cell} / \mathrm{mm}^{3}$ $(\mathrm{OR}=27.6,95 \% \mathrm{CI} 3.1-247.1)$ was independently associated with HIV seropositivity among pulmonary TB patients.

The follow-up period median was 216 days (range 21260 days). Twenty-four pulmonary TB patients (27.9\%) died during the follow-up period; $65.2 \%$ of the HIV-se- ropositive patients (15/23) versus $14.3 \%$ of HIV-seronegative patients (9/63). After 350 days of follow-up, the probability of survival among HIV-seronegative pulmonary TB patients was $80 \%$, but only $49.4 \%$ among HIVseropositive $(P<0.001, \log$-rank test $)$.

In the Cox regression model fitted to all pulmonary $\mathrm{TB}$ patients, HIV seropositivity and age were independently associated with decreased survival. When age was used as a covariate in the Cox regression model, the estimated relative hazard $(\mathrm{RH})$ due to seropositivity was $6.49(P=$ $0.0001)$. This is much larger than the $\mathrm{RH}=4.20(P=0.0007)$ obtained by a model containing the HIV serostatus alone. This can be explained by the confounding effect of age:

TABLE

Characteristics of 86 smear-positive pulmonary tuberculosis patients associated with HIV seropositivity in the univariate analysis

\begin{tabular}{|c|c|c|c|c|}
\hline Characteristics & $\begin{array}{c}\text { HIV-seropositive } \\
(\%)\end{array}$ & $\begin{array}{c}\text { HIV-seronegative } \\
(\%)\end{array}$ & $\begin{array}{l}\text { Odds Ratio } \\
\text { (95\% C.I.) }\end{array}$ & $\begin{array}{c}P \\
\text { value }\end{array}$ \\
\hline \multicolumn{5}{|l|}{ Gender } \\
\hline Male & $19(82.6)$ & $40(63.5)$ & $2.73(0.75-10.86)$ & \multirow[t]{2}{*}{0.12} \\
\hline Female & $4(17.4)$ & $23(36.5)$ & 1 & \\
\hline \multicolumn{5}{|l|}{ Race } \\
\hline White & $13(56.5)$ & $42(66.7)$ & $1.54(0.58-4.09)$ & \multirow[t]{2}{*}{0.45} \\
\hline Non white & $10(43.5)$ & $21(33.3)$ & 1 & \\
\hline \multicolumn{5}{|c|}{$25 \mathrm{yrs} \leq \mathrm{Age} \leq 45 \mathrm{yrs}$} \\
\hline Yes & $17(73.9)$ & $29(46.0)$ & $3.32(1.16-9.53)$ & \multirow[t]{2}{*}{0.03} \\
\hline No & $6(26.1)$ & $34(54.0)$ & 1 & \\
\hline \multicolumn{5}{|l|}{ Fever } \\
\hline Yes & $19(82.6)$ & $44(69.8)$ & $2.05(0.61-6.84)$ & \multirow[t]{2}{*}{0.28} \\
\hline No & $4(17.4)$ & $19(30.2)$ & 1 & \\
\hline \multicolumn{5}{|l|}{ Productive cough } \\
\hline Yes & $11(47.8)$ & $40(63.5)$ & $0.53(0.20-1.38)$ & \multirow[t]{2}{*}{0.22} \\
\hline No & $12(52.2)$ & $23(36.5)$ & 1 & \\
\hline \multicolumn{5}{|c|}{ Cough $\geq 4$ weeks } \\
\hline Yes & $13(56.5)$ & $44(69.8)$ & $0.56(0.21-1.50)$ & \multirow[t]{2}{*}{0.30} \\
\hline No & $10(43.5)$ & $19(30.2)$ & 1 & \\
\hline \multicolumn{5}{|c|}{ Bloody sputum/hemoptysis } \\
\hline Yes & $4(17.4)$ & $22(34.9)$ & $0.39(0.12-1.30)$ & \multirow[t]{2}{*}{0.18} \\
\hline No & $19(82.6)$ & $41(65.1)$ & 1 & \\
\hline \multicolumn{5}{|c|}{ Weight loss $\geq 10 \%$} \\
\hline Yes & $15(83.3)$ & $27(57.5)$ & $3.70(0.94-14.54)$ & \multirow[t]{2}{*}{0.08} \\
\hline No & $3(16.7)$ & $20(42.5)$ & 1 & \\
\hline \multicolumn{5}{|l|}{ Alcoholism } \\
\hline Yes & $5(21.7)$ & $9(14.3)$ & $1.67(0.42-6.47)$ & \multirow[t]{2}{*}{0.51} \\
\hline No & $18(78.3)$ & $54(85.7)$ & 1 & \\
\hline \multicolumn{5}{|c|}{ Total lymphocyte $\leq 1000 / \mathrm{mm}^{3}$} \\
\hline Yes & $12(52.2)$ & $13(20.6)$ & $4.20(1.51-11.64)$ & \multirow[t]{2}{*}{0.007} \\
\hline No & $11(47.8)$ & $50(79.4)$ & 1 & \\
\hline \multicolumn{5}{|c|}{$\mathrm{CD} 4+\leq 200 / \mathrm{mm}^{3} a$} \\
\hline Yes & $11(64.7)$ & $3(5.2)$ & $33.61(7.28-155.17)$ & \multirow[t]{2}{*}{$<0.0005$} \\
\hline No & $6(35.3)$ & $55(94.8)$ & 1 & \\
\hline \multicolumn{5}{|l|}{ Anergy $b$} \\
\hline Yes & $10(50.0)$ & $1(1.9)$ & $52.00(5.97-452.78)$ & \multirow[t]{2}{*}{$<0.0005$} \\
\hline No & $10(50.0)$ & $52(98.1)$ & 1 & \\
\hline \multicolumn{5}{|l|}{ PPD negativity ${ }^{c}$} \\
\hline Yes & $16(80.0)$ & $20(37.0)$ & $6.80(2.0-23.2)$ & 0.001 \\
\hline No & $4(20.0)$ & $34(63.0)$ & 1 & \\
\hline Atypical chest $r$ & & & & \\
\hline Yes & $14(63.6)$ & $15(24.6)$ & $5.37(1.88-15.27)$ & 0.002 \\
\hline No & $8(36.4)$ & $46(75.4)$ & 1 & \\
\hline
\end{tabular}

$a: \mathrm{n}=75 ; b: \mathrm{n}=73 ; c: \mathrm{n}=74 ; d: \mathrm{n}=83$ 
HIV-seropositive patients tend to be younger than HIVnegative ones, and young age tends to protect patients against death. Age is estimated to increase the mortality by approximately $5 \%$ for every additional year of life $(\mathrm{RH}$ $=1.05 ; P=0.002$.

Age was dichotomized at age 50 years to assess graphically the effect of age on the risk of death by different survival curves. We choose 50 years as the cut off to demonstrate the effect of aging in the risk of death by TB and separate the patients into sufficiently numerous groups for analysis. In this model, HIV seropositivity and age $\geq 50$ years were independently associated with decreased survival $(\mathrm{RH}=5.4,95 \% \mathrm{CI} 2.3-12.9$ and $\mathrm{RH}=4.1$, $95 \%$ CI 1.6-10.2, respectively). Figure shows four survival curves representing the pulmonary TB patients by HIV serostatus and age category. The lowest probability of survival was among HIV-seropositive pulmonary TB patients $\geq 50$ years of age, and was highest among HIVseronegative pulmonary TB patients $<50$ years old.

Among pulmonary TB patients who were HIV-seronegative, the presence of an additional disease increased the risk of death of almost six-fold $(\mathrm{RH}=5.6,95 \%$ CI 1.422.7). Use of antiretroviral drugs was associated with a lower risk of death among HIV-seropositive smear-positive TB patients $(\mathrm{RH}=0.32,95 \% \mathrm{CI} 0.10-0.92)$.

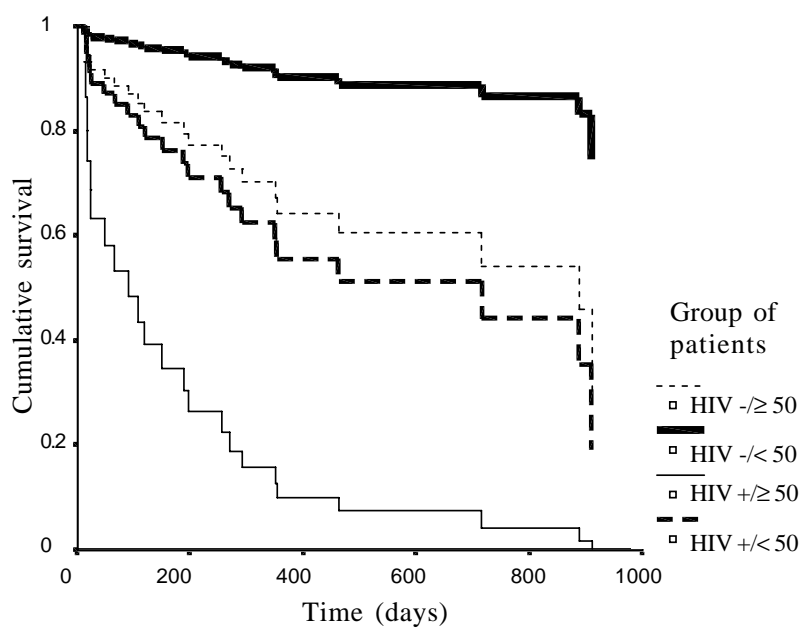

Cox regression model's probability of survival among smear-positive pulmonary tuberculosis patients (PTP), by HIV serostatus and age group (Kaplan Meier-type curves obtained with the proportional hazard assumption).

\section{DISCUSSION}

Our main objective in this study was to evaluate the clinical presentation, laboratory findings and short-term survival of smear-positive pulmonary TB patients by human immunodeficiency virus infection serostatus. The study population of pulmonary TB patients was characterized by a high rate of HIV-seropositivity, associated comorbidities and a low short-term survival rate.

The prevalence of HIV-seropositivity among pulmonary TB patients (26.7\%) in our study was lower than that reported in a hospital based population in New York city (Stoneburner et al. 1992), but was higher than that previously described among patients seeking health care in outpatient community health centers in Rio de Janeiro city. The prevalence was approximately $1.5 \%$ in 1988 (Kritski et al. 1991), increasing to $11.2 \%$ in 1994 (Silva et al. 1998).

TB accelerates the course of HIV-infection and may contribute to the mortality of HIV-infected individuals by a one to two-fold increase, as described in two cohortbased studies of HIV-patients (Whalen et al. 1995, Perneger et al. 1995). The presence of newly diagnosed HIV-infection also reduced the probability of survival among TB patients (Ackah et al. 1995, Alpert et al. 1997).

The majority of HIV-seropositive pulmonary TB patients in our study presented advanced immunodeficiency, expressed by a low CD4+ cell count, anergy and atypical chest radiography. This is similar to the characteristics of hospitalized patients coinfected with HIV and TB, including extrapulmonary $\mathrm{TB}$, in other industrialized countries (Chaisson et al. 1987, Daley 1995) but is different from the pattern reported among ambulatory, outpatient pulmonary TB patients in Africa, where TB often developed in earlier stages of HIV-infection (Mukadi et al. 1993, Ackah et al. 1995). The severity of immunodeficiency among TBHIV coinfected patients has been described as a predictor of decreased survival (Shafer et al. 1996, Whalen et al. 1996, Alpert et al. 1997) and was likely the main determinant of death in our HIV-infected pulmonary TB patients. Although the size of our HIV-seropositive population was limited, the use of antiretroviral drugs, even when started after the TB diagnosis, increased the short-term survival. Information about prophylaxis for opportunistic infections was not recorded, therefore its impact on the mortality of smear-positive pulmonary TB patients could not be evaluated.

A total lymphocyte count $\leq 1000$ cells $/ \mathrm{mm}^{3}$ was associated with HIV-seropositivity among pulmonary TB patients in the univariate analysis. This data reinforces the usefulness of total lymphocyte count as a substitute for CD4+ cell analysis in middle and low income countries, as previously described (Sloan et al.1991, Blatt et al. 1993). The total lymphocyte count is cheaper, more widely available, and has been indicated as a prognostic marker of mortality among TB-HIV coinfected patients (Whalen et al. 1996, Wood \& Post 1997).

The independent association of chronic diseases or co-morbidities with survival among persons with pulmonary TB was another relevant finding of our study. Most of these co-morbidities are predisposing conditions for the reactivation of latent $\mathrm{TB}$, are more common among elderly persons and may motivate the patient to seek health care and treatment (Haanaes \& Bergmann 1983, Stead et al. 1985, Rao et al. 1998). A TB diagnosis in these patients could actually be delayed due to the presence of other, more exuberant extra-pulmonary symptoms and atypical presentation. Late recognition of TB, associated with the decreased immunity inherent to some of these diseases, could have contributed to the higher mortality rate found among these patients. 
Our study has some limitations. First, we could not ascertain the cause of death among our patients, and therefore we cannot attribute their deaths with certainty to TB and/or to another additional disease, including complications of HIV infection. Second, our patients were not under directly observed, short course therapy (DOTS); we were not able to accurately assess the role of anti-TB treatment defaulting on survivorship. Third, due to the absence of a structured TB control program and a micobacteriology laboratory, mycobacterial cultures were not available. Therefore, our study was limited to patients whose TB was bacteriologically confirmed by the smear examination for acid-fast bacilli. Because the sputum smear is not as sensitive as culture for Mycobacterium tuberculosis, diseased persons with negative smears were excluded. Previous study performed in the same university hospital in Rio de Janeiro showed that the positive predictive value of the acid-fast smear for M. tuberculosis was $98.4 \%$ in expectorated sputum and $96.5 \%$ in bronchoalveolar lavage, despite the high prevalence of HIV seropositivity (Conde et al. 1999). Fourth, drug susceptibility tests were not available. The presence of multidrug-resistant TB (MDR-TB) could increase mortality among HIV-seropositive pulmonary TB patients, and high case-fatality rates among hospitalized HIV-seropositive patients with MDR-TB have been described elsewhere (Edlin et al. 1992, Fischl et al. 1992). In 1993 and 1994, the prevalence of primary MDR-TB in general hospitals in Rio de Janeiro city varied from 5\% among HIV-seronegative TB patients to $12 \%$ in HIV-seropositive ones (Fandinho et al. 1999). The data showed a higher prevalence of MDR-TB than that observed among TB patients followed in outpatient clinics and who were sampled in a national survey for antituberculosis-drug resistance coordinated by WHO's Global Program and the National TB Control Program in Brazil. The prevalence of primary and acquired MDR-TB found in this survey were $0.9 \%$ and $5.4 \%$, respectively (Pablos-Mendes et al. 1998).

In conclusion, the smear-positive pulmonary TB patients evaluated in our hospital had a low short-term survival that was significantly associated with age $\geq 50$ years and the presence of co-morbidities, mainly HIV coinfection. Patients with TB should be assessed for HIV infection whenever possible. In Brazil, highly active antiretroviral drugs are now available for HIV-infected patients. Early recognition of HIV infection among TB patients could help to reduce its negative impact on TB patients' survival, offering the opportunity for more appropriate therapy of both diseases.

\section{REFERENCES}

Ackah A, Coulibaly D, Digbeu H, DialloK, Vetter KM, Coulibaly IM, Greenberg AE, De Cock KM 1995. Response to treatment, mortality, and CD4 lymphocyte counts in HIV-infected persons with tuberculosis in Abidjan, Côte d'Ivoire. Lancet 345: 607-610.

Alpert PL, Munsiff SS, Gourevitch MN, Greenberg B, Klein RS 1997. A prospective study of tuberculosis and human immunodeficiency virus infection: clinical manifestations and factors associated with survival. Clin Infect Dis 24: 661-668.
Blatt SP, Lucey CR, Butzin CA, Hendrix CW, Lucey DR 1993. Total lymphocyte count as a predictor of absolute CD4+ count and CD4+ percentage in HIV-infected persons. JAMA 269: 622-626.

Cavalcante SC, Pacheco AG, Lauria L, DeRiemer K, Durovni B 1998. Epidemiologia da tuberculose no município do Rio de Janeiro: revisão dos casos notificados de 1995-1997. Boletim de Pneumologia Sanitária 6: 81-92.

Chaisson RE, Schecter GF, Theuer CP, Rutherford GW, Echenberg DF, Hopewell PC 1987. Tuberculosis in patients with the acquired immunodeficiency syndrome: clinical features, response to therapy and survival. Am Rev Respir Dis 136: $570-574$.

Conde MB, Figueira CM, Moraes R, Fonseca LS, Deriemer K, Kritski AL 1999. Predictive value of the acid fast smear for detection of Mycobacterium tuberculosis in respiratory specimens in a Reference Center of HIV/AIDS in Rio de Janeiro, Brazil. Mem Inst Oswaldo Cruz 94: 787-790.

Daley CL 1995. The typically "atypical" radiographic presentation of tuberculosis in advanced HIV disease. Tuberc Lung Dis 76: 475-476.

Dye C, Scheele S, Dolin P, Pathania V, Raviglione MC 1999. Global burden of tuberculosis. Estimated incidence, prevalence, and mortality by country. JAMA 282: 677-686.

Edlin BR, Tokars JI, Grieco MH, Crawford JT, Williams J, Sordillo EM, Ong KR, Kilburn JO, Dooley SW, Castro KG, Jarvis WR, Holmberg SD 1992. An outbreak of multidrug-resistant tuberculosis among hospitalized patients with the acquired immunodeficiency syndrome. $N$ Engl J Med 326: 1514-1521.

Fandinho F, Kritski A, Hofer C, Conde Jr H, Ferreira R, Silva M, Fonseca L 1999. Drug resistance patterns among hospitalized tuberculosis patients in Rio de Janeiro, Brazil, 1993-1994. Mem Inst Oswaldo Cruz 94: 543-547.

Fischl MA, Uttamchandani RB, Daikos GL, Poblete RB, Moreno JN, Reyes RR, Boota AM, Thompson LM, Cleary TJ, Lai S 1992. An outbreak of tuberculosis caused by multipledrug-resistant tubercle bacilli among patients with HIV infection. Ann Int Med 117: 177-183.

Haanaes OC, Bergmann A 1983. Tuberculosis emerging in patients treated with corticosteroids. Eur J Resp Dis 64: 229237.

Kritski A, Barroso EW, de Souza RB, Andrade GN, Pena ML, Castilho EA, Galvão-Castro B 1991. Tuberculosis and HIV infection in Rio de Janeiro, Brazil. AIDS 5: 107-108.

Mukadi Y, Perriens JH, St Louis ME, Brown C, Prignot J,Willame JC, Pouthier F, Kaboto M, Ryder RW, Portaels F, Piot P 1993. Spectrum of immunodeficiency in HIV-1 infected patients with pulmonary tuberculosis in Zaire. Lancet 342: 143-146.

Pablos-Mendez A, Raviglione MC, Laszlo A, Binkin N, Rieder HL, Bustreo F, Cohn DL, Lambregts-van Weezenbeek CS, Kim SJ, Chaulet P, Nunn P 1998. Global surveillance for antituberculosis-drug resistance, 1994-1997. N Engl J Med 338: 1641-1649.

Perneger TV, Sudre P, Lundgren JD, Hirschel B 1995. Does the onset of tuberculosis in AIDS predict shorter survival? Results of a cohort study in 17 European countries over 13 years. BMJ 311: 1468-1471.

Rao VK, Iademarco EP, Fraser VJ, Kollef MH 1998. The impact of comorbidity on mortality following in-hospital diagnosis of tuberculosis. Chest 114: 1244-1252.

Shafer RW, Bloch AB, Larkin C, Vasudavan V, Seligman S, Dehovitz JD, Di Ferdinando G, Stoneburner R, Cauthen G 1996. Predictors of survival in HIV-infected tuberculosis patients. AIDS 10: 269-272. 
Silva G, Barreira D, Soares ECC, Dias SMO, Saavedra A 1998. HIV seropositivity among patients with tuberculosis in the city of Rio de Janeiro. Conference Record, XII International Conference on AIDS, abstract 13272.

Sloan P, Carlin J, Crowse S M 1991. Total lymphocyte count can predict low CD4: a useful substitute for T-subset analysis. Conference Record, VII International Conference on AIDS, abstract WB 409.

Stead WW, Lofgren JP, Warren E, Thomas C 1985. Tuberculosis as an endemic and nosocomial infection among the elderly in nursing homes. N Engl J Med 312: 1483-1487.

Steinweg DL, Worth H 1993. Alcoholism: the keys to the CAGE. Am J Med 94: 520-523.

Stoneburner R, Laroche E, Prevots R, Singh T, Blum S, Terry P, Reatrice S, Adler J 1992. Survival in a cohort of human immunodeficiency virus-infected tuberculosis patients in New York city: implications for the expansion of the AIDS case definition. Arch Intern Med 152: 20332037.

Szwarcwald CL, Bastos FI, Castilho EA 1998. The dynamics of the AIDS epidemic in Brazil: a space-time analysis in the period 1987-1995. Braz J Infect Dis 2: 175-186.

Whalen C, Horsburgh CR, Hom D, Lahart C, Simberkoff M, Ellner J 1995. Accelerated course of human immunodeficiency virus infection after tuberculosis. Am J Respir Crit Care Med 151: 129-135.

Whalen C, Okwera A, Johnson JL, Vjecha M, Hom D, Wallis R, Huebner R, Mugerwa R, Ellner J 1996. Predictors of survival in human immunodeficiency virus-infected patients with pulmonary tuberculosis. Am J Respir Crit Care Med 153: 1977-1981.

Wood R, Post FA 1997. Survival of human immunodeficiency virus-infected persons with pulmonary tuberculosis [letter]. Int J Tuberc Lung Dis 1: 87. 